\title{
"Green" Chemistry as the Basis for Development of the Philosophy of Sustainable Education in an Agricultural University
}

\author{
Marina Grigoryeva*, Sergey Belopukhov, Inna Dmitrevskaya, Inga Seregina \\ Russian State Agrarian University-Moscow Agricultural Academy named after K.A. Timiryazev, Moscow, Russia \\ ${ }^{*}$ Corresponding author. Email: marina_gry@inbox.ru
}

\begin{abstract}
The expediency of including the philosophy of green chemistry in the educational process in teaching agricultural students has been substantiated. Examples of studies aimed at using the principles of green chemistry in agricultural production are given. Use of natural low-toxic drugs as pesticides and plant growth stimulants. Development of methods for processing the agricultural waste. Thermochemical study in the field of agriculture. Study of catalytic processes. Development of test methods for timely control of agricultural objects. The experience of using the principles of green chemistry in teaching chemical disciplines to agrarian students is provided. The additions to the content of the topics "Thermochemistry", "Catalytic processes" are shown in the context of the formation of students' readiness to solve professional tasks to minimize energy costs in agriculture and use their own renewable energy sources.
\end{abstract}

Keywords: chemical training of specialists in the agro-industrial complex, "green" chemistry, sustainable education, sustainable development.

\section{INTRODUCTION}

Everyone understands the priority of the tasks related to preservation of the health of our planet. Ecocentric thinking must be at the core of the learning process of the younger generation. This is all the more important when we are talking about future agricultural specialists, whose professional activities are associated with an active impact on the environment. The concept of sustainable development involves the development of issues that determine the sustainability, durability of any technologies and processes carried out for the benefit of the person. The needs of the present generation must be met in such a way as not to limit or jeopardize the ability to meet the needs of future generations. For this concept to be implemented in reality, the education system must be based on the principles that determine sustainable development, which was noted by UNISEF as one of the tasks in the reform of education systems. In agricultural universities (as well as in many other areas of higher education), green chemistry can be a key component of sustainable education. In our country, the study of the principles of green chemistry began mainly with the training of chemists (Moscow State University named after M.V. Lomonosov, Russian University of Chemical
Technology named after D.I. Mendeleev), which is understandable and expedient. Wherein, we believe that future specialists in the agro-industrial complex shall also be guided in their professional activities by the principles of sustainable development and green chemistry. Agricultural production is based on knowledge of physical and chemical natural processes and the ability to control them. The philosophy of managing agricultural processes based on the principles of sustainable development is currently an urgent need.

Green chemistry is a new way of thinking in the field of chemical and other technologies based on use of chemical processes. These are new ways to address environmental issues. Wherein, this is not a rejection of chemistry, it is development of new technologies, new materials, new energy carriers based on the philosophy of sustainable development.

\section{MATERIALS AND METHODS}

The research methodological base is based on the concept of sustainable development and the principles of green chemistry. We relied on the provisions of $\mathrm{H}$. Brundtland in defining the tasks of the concept of sustainable development, as well as on the principles of 
green chemistry, formulated by P. Anastas and J. Warner [1-3]. The papers of V.V. Lunin, E.S. Lokteva and E.V. Golubina [4], L.M. Kustov and I.P. Beletskaya [5] made it possible to get acquainted with the experience of the development of green chemistry in Russia.

The practical implementation of the study results was carried out at the Russian State Agrarian UniversityMoscow Agricultural Academy named after K.A. Timiryazeva (RSAU-MAA) (Moscow).

\section{RESULTS AND DISCUSSION}

The twelve principles of green chemistry formulated by Anastas and Warner [1] are widely known. They relate to any production related to use of chemical processes. Most of them are applicable to agricultural production. We offer examples of the application of the principles of green chemistry in the educational process of agricultural students for consideration.

It is better to prevent formation of emissions and byproducts than to recycle, clean up or dispose them.

Students shall be conveyed the idea that agricultural production is designed not only to produce some kind of product, but at the same time, shall not leave waste. For this, the Department of Chemistry of the RSAU-MAA is developing methods for processing agricultural waste. Since this year, the University has established the Institute of Agrobiotechnology, which unites all the main departments. Therefore, undergraduate and graduate students of different areas of training (agrochemistry and agrosoil science, agronomy, biotechnology, meteorology), performing their final qualification works and other study tasks, are in a single organizational and methodological structure [6]. Within the framework of one institute, studies in the Soil-Plants-Animals-Human chain is possible. These studies are aimed at minimizing material and energy costs in order to obtain high-quality agricultural products with an optimal chemical composition. For example, with the participation of students, the studies has been carried out on the processing of hemp fires. Methods for extracting soluble substances from it are offered. Formulations for the manufacture of building materials (slabs, bricks) with the addition of hemp fire have been developed. This paper has not only environmental benefits, but also functional, technological and economic ones.

An important area of the study is study of the sorption characteristics of soils and sorbents which are obtained from cellulose-containing plant biomass. Urgency study sorption characteristics of data objects with respect to various gases and vapors of volatile substances, among other factors, determined by the fact that the soil biomass and plant capable of accumulating $\mathrm{CO}_{2}$ and toxic gases, which helps to reduce their concentration in the atmosphere of the planet.
Whenever possible, use substances with minimal toxicity to humans and the environment.

RSAU-MAA named after K.A. Timiryazev, active work is currently underway to train specialists for organic agriculture. Accordingly, research and educational activities are being conducted in this direction [7]. One of the current developments is devoted to the study of drugs allowed in organic agriculture. Together with the students, information on the physicochemical, toxicological properties of the active substances of the preparations allowed for use in organic farming and animal husbandry has been systematized. The mechanisms of their action are being studied. Investigated drugs, the active substance of which are substances isolated from plants. Azadirachtin, derived from Azadirachta indica, and used as an insecticide. Peretrines obtained from Chrysanthemum cinerariaefolium. Insecticides and repellents made from Quassia amara. Rotenone based insecticides obtained from Derris elliptica, Lonchocarpus spp, Thephrosia spp. Preparations based on Ryania speciosa.

The chemicals produced must be selected so as to maintain their functional effectiveness while reducing toxicity.

Compliance with this principle is very important when creating and using agrochemicals, for example, plant protection products of narrowly targeted action. If the mechanism of action of an agricultural product is known, then it is possible to create a similar substance that has that functional group or a fragment of the structure that participates in the process and determines its action, while toxicity shall be reduced. The Department of Chemistry is engaged in the synthesis of new compounds, guided by this principle. Work is performed to create and study protective-stimulating complexes, the main criterion of which is their safety.

Requirements for environmental safety when using mineral fertilizers shall also increase. Phosphate fertilizers that are widely used for cultivation of various crops were selected as one of the study objects. To obtain phosphoric fertilizers, phosphoric acid purified using organic solvents is often used. At the Department of Chemistry, RSAU-MAA, work was carried out to find the most effective method for purifying phosphoric acid for the subsequent synthesis of phosphoric fertilizer. On its basis, the fertilizer magnesium-ammonium phosphate $\left(\mathrm{MgNH}_{4} \mathrm{PO}_{4}\right)$ was then synthesized, which was used for growing tomatoes. This study is also closely related to the following tenet of green chemistry:

\section{Use of harmless excipients (solvents, extractants).}

Consideration of the properties of water as the most demanded solvent in agriculture is provided for in traditional discipline programs. In the process of teaching chemical disciplines, students are introduced to new 
solvents (for example, $\mathrm{CO}_{2}$ in a supercritical state), which may soon take their place in agricultural production.

Energy costs must be reassessed in terms of economy and environmental impact and minimized.

Efficient use and recovery of heat is one of the most important tasks of modern mankind, which has both an ecological and an economic perspective. Traditionally obtained heat, on the one hand, is quantitatively equivalent to consumed oil and gas, and on the other hand, carbon dioxide emissions into the atmosphere. Therefore, it is difficult to overestimate the importance of this issue, including in the agricultural sector. One of the research areas of the Department of Chemistry of the Russian State Agrarian University-Moscow Agricultural Academy named after K.A. Timiryazeva is determination of thermodynamic characteristics $(\Delta H, \Delta S, \Delta G)$ for processes occurring in biological systems. For this, a thermo-analytical complex has been developed at the department, which allows for each of the initial substances and reaction products to determine the thermodynamic characteristics, to quantify the thermochemical effect (exo or endo) of the process and to develop recommendations for reducing energy costs for carrying out certain biochemical reactions.

In studies of various types of soils in Russia, it is very important to assess the energy of interaction of soil particles with water, to assess the thermodynamics of the dissolution process of macro- and micronutrient fertilizers. Considering that at the field experimental station of the RSAU-MAA named after K.A. Timiryazev grows and tests more than 200 agricultural crops in crop rotation and in a permanent mode, it is practically important to observe the transformation of the soilabsorbing complex. Therefore, every year students receive samples from the field station and assess the agrochemical properties of the soil. Thus, the dynamics of changes in thermodynamic and other soil characteristics are monitored [7]. Educational and research activities of students are in constant interaction $[8,9]$.

We believe that all students of an agricultural university shall study the basics of thermochemistry. It is advisable to supplement the theoretical material with the principles of heat management and information on alternative renewable energy sources. This is all the more relevant specifically for agriculture, since waste from this industry can be a source for generating heat. Cellulose and other types of biomass, vegetable oils - an incomplete list of raw materials suitable for these purposes.

Use of renewable rather than exhaustible resources whenever possible and economically feasible.

Agriculture has significant resources to develop a strategy for switching to renewable raw materials and fuels. This is highly relevant in the context of the depletion of oil, natural gas and coal reserves. Students must learn in the context of these world aspirations.

Lignocellulose and starch obtained from plant biomass are important renewable raw materials. The sugars obtained from them can be enzymatically processed into organic acids (lactic, oxalic, citric, etc.), which, in turn, can be used in further chemical syntheses.

\section{Use of catalytic systems and processes.}

At the Department of Chemistry of the Russian State Agrarian University-Moscow Agricultural Academy named after K.A. Timiryazev, research is being carried out related to the intensity of plant growth and development. We ourselves develop and research, or test on orders from other organizations, the catalysts of their processes - plant growth regulators. The active ingredients of these drugs affect the dynamics of plant growth and development, including the increase in biomass. For industrial crops such as fiber flax - to increase the cellulose content in the fiber and to reduce the concentration of lignin. This is very important because it becomes possible to reduce the growing season. For example, for fiber flax, from 90 days to 80 days, with obtaining identical yields for fiber and seeds [10].

The action of growth regulators affects the intensity of seed germination and growth rate at the initial stages of plant development. We offered to describe the growth dynamics of industrial crops seedlings through a kinetic equation in the form of the 6th degree polynomial, where the coefficient at the linear term corresponds to the effective growth constant. Wherein, carrying out the germination process at different temperatures makes it possible to determine the activation energy and thermodynamic characteristics of the germination process.

One of the environmentally friendly drugs we investigated is Rafitour. It is a plant extract obtained from the juvenile Impala potato. It has a growth-stimulating and immunomodulatory effect. Rafitour is a balanced protein-carbohydrate complex containing glycosides, free hydroxycarboxylic and amino acids, micro- and macroelements, and phytohormones. The effect of the drug has been investigated on various crops, including successful tests carried out on flax. The experimental results showed a positive effect of this drug on the rate of seed germination, the dynamics of plant growth and development, as well as on the content of proteins and lipids in the composition of seeds [10].

Analytical control methods are necessary in real time to prevent the harmful substance formation.

Analytical methods in agricultural production are currently in high demand for various reasons [6]. One of the most important is environmental control over the state of objects in the agrosphere (soils, water sources, air, 
etc.). Students study the methods of chemical and instrumental analysis in the relevant undergraduate disciplines. Textbooks have been created on the methods of analysis used for agricultural production facilities. Traditionally, in RSAU-MAA named after K.A. Timiryazev, there is a voluminous laboratory workshop on analytical chemistry. In addition, for more than 10 years the master's program "Chemical-toxicological and microbiological analysis of objects of the agrosphere" has been in high demand. Analytical instruments and equipment make it possible to acquaint students with the most modern methods of analysis: near infrared spectroscopy, scanning electron microscopy in conjunction with energy dispersive analysis, thermogravimetry and other physicochemical methods that allow for express analysis of the quality of agricultural products. A number of educational and reference-methodological manuals have been developed, where the application of analytical methods in agricultural study is considered in detail.

At the Department of Chemistry of the Russian State Agrarian University-Moscow Agricultural Academy named after K.A. Timiryazeva the special attention is paid to development of analytical test methods for agricultural facilities. Comprehensive studies are being carried out to develop test methods for the analysis of cations, anions and complex compounds. A blistercolorimetric version of determination of phosphate ions in a blister cell containing a mixture of dry reagents in the form of a mash is offered. The method allows the semiquantitative determination of phosphorus in various objects without preparation of reagent solutions, using a bulk packed in an ampoule or blister. This method can be used to control the phosphorus consumption of plants, which, in turn, allows to regulate introduction of nutrients in the form of dressings.

\section{CONCLUSION}

The current state of the planet requires from all of us a priority choice in favor of the most environmentally friendly solutions in the field of any technology and production, including agriculture. The recognized and disseminated concept of sustainable development can be implemented in the field of agricultural production by applying the principles of green chemistry. In order for modern agriculture to be able to apply the principles of green chemistry in practice, first of all, the following is necessary:

1. Scientific studies aimed at development of new, more environmentally friendly methods, technologies, materials that allows to more carefully treat natural resources while maintaining and improving productivity.

2. Systemic educational activities aimed at formation of future specialists in the agro-industrial complex: sustainable ecocentric ideological attitudes, understanding the value of nature and the need to respect it; a certain set of knowledge in the field of green chemistry, based on the latest scientific advances; experience in practical and research activities in which the principles of the concept of sustainable development and green chemistry are implemented.

RSAU-MAA named after K.A. Timiryazev also carries out study and educational works in the field of green chemistry. Methods for processing agricultural waste are being developed; the sorption capacity of soils and plant biomass is being studied; the possibility of replacing toxic agrochemicals (pesticides, plant growth stimulants) with safer ones is being investigated; syntheses are carried out and new methods of purification of substances are developed according to the principles of green chemistry; determination of the thermodynamic characteristics of soils and biochemical processes is carried out for various purposes, including to identify ways to reduce energy costs; analytical test methods are being developed, and etc.

When arranging the educational activities, attention is paid to formation of an appropriate worldview, basic chemical courses are supplemented with information about research by scientists in the field of green chemistry, research tasks in this direction. The thermochemistry classes address issues related to alternative renewable energy sources derived from agricultural waste. When studying the catalytic processes, their advantage over stoichiometric reactions is substantiated, examples of catalytic processes in agricultural production are given. The active use of project-based learning allows students to gain experience in practical and research activities necessary to form the ability and readiness to solve problems in future professional activities, guided by the philosophy of green chemistry.

\section{ACKNOWLEDGMENTS}

The work was carried out in accordance with the theme of the grant of the World-class Scientific Center "Agricultural Technologies of the Future" (Order of the Government of the Russian Federation of October 24, 2020).

\section{REFERENCES}

[1] P.T. Anastas, J.C. Warner, «Green Chemistry: Theory and Practice», Oxford University Press, 1998.

[2] P. Anastas, Green Chem., 2003 p. 29.

[3] P. Anastas, L.B. Bartlett, M.M. Kirchhoff, T.C. Williamson, Catal. Today 55 (2000) p. 11.

[4] Innovative educational programs in the field of chemistry. Scientific and educational center. 
"Chemistry for sustainable development - green chemistry", Publishing house of Moscow State University, 2007, p. 117.

[5] L.M. Kustov, I.P. Beletskaya, "Green Chemistry is New Thinking. Ros. chem. 6 (2004) pp. 3-12.

[6] M.V. Grigoryeva, S.L. Belopukhov, Chemical disciplines in the system "bachelor's - master's postgraduate studies of an agricultural university". History and Pedagogy of Natural Science, 2 (2020) pp. 5-8. DOI: https://doi.org/10.24411/2226-22962020-10201.

[7] S.L. Belopukhov, M.V. Grigoryeva, I.I. Dmitrevsk aya and A.V. Zhevnerov, Agroecological approach to quality assessment of organic aromatic products, In: International Conference "Ensuring Food Security in the Context of the COVID-19 Pandemic" (EFSC2021) E3S Web of Conferences, 2021. DOI: https://doi.org/10.1051/e3sconf/202128 202004.

[8] S.L. Belopukhov, S.E. Starykh, A.N. Kupriyanov, M.V. Grigoryeva, Investigation of the qualitative composition of humic acids in sod-podzolic soil by thermal analysis. Environmental Management, 3 (2020) pp. 36- 45. DOI: https://doi.org/10.26897/1 997-6011-2020-3-36-45.

[9] M.V. Grigoryeva, N.L. Bagnavets, S.L. Belopukh ov. Design work in training under the master's program "Chemical and Toxicological Analysis of Objects of the Agrosphere". Agroengineering, 2(96) (2020) pp. 64 - 69. DOI: https://doi.org/10.26 897/2687-1149-2020-2-64-69.

[10] M.V. Grigoryeva, N.L. Bagnavets, S.L. Belopukh ov. Educational and research work of students as a component of the system of continuity between bachelor's and master's degrees. History and Pedagogy of Natural Science, 2021, 1(2) (2021) pp. 5-10. DOI: https://doi.org/10.24412/2226-22962021-1-2-5-10.

[11] I.I. Dmitrevskaya, S.L. Belopukhov, N.L. Bagnavet s, M.V. Grigoryeva. Application of the plant growth stimulator Rafitour for the cultivation of flax. Agrochemical Bulletin 3 (2020) pp. 53-56. DOI: https://doi.org/10.24411/1029-2551-202010040 . 